\title{
Correspondence
}

\section{Flexible cystofibrescope for difficult intubation}

To the Editor:

We recently used a flexible cystofibrescope (OlympusCYF $^{\mathbb{}}$ ) to intubate the trachea of an adult in the cystoscopy suite. The patient was an adult male scheduled for a transurethral resection of a bladder tumour. Following administration of thiopentone and succinylcholine, several attempts at direct laryngoscopy and tracheal intubation were unsucessful. The lungs were easy to ventilate via mask and bag. With the return of spontaneous ventilation while the patient breathed a mixture of isoflurane, nitrous oxide and oxygen, it was decided to use a flexible fibreoptic laryngoscope to aid intubation. Since our cystoscopy suite is in a different part of the building from the main operating rooms, it would have taken us some time to obtain the flexible laryngoscopy apparatus from the operating suite. However, a flexible cystofibrescope, already sterilized and ready for the planned cystoscopy, was available and we decided to use it instead. The trachea was successfully intubated using this flexible cystoscope through an $8 \mathrm{~mm}$ ID endotracheal tube with the patient still breathing spontaneously and anaesthetized with isoflurane and nitrous oxide. Since this incident we have employed the same fibreoptic endoscope successfully for another elective tracheal intubation in the urology suite.

The flexible endoscope used in both of these instances is the Olympus CYF fibrescope ${ }^{\boxplus}$ wich features high resolution optics with a wide angle lens system and an angulation system that allows easy orientation and detailed observation. Its main specifications ${ }^{1}$ (see Table) suggest that it can be easily adapted to perform flexible laryngoscopy and tracheal intubation in most adults.

TABLE Main specifications of CYF ${ }^{\circledR}$ cystofibrescope ${ }^{1}$

\begin{tabular}{lll}
\hline Optical system & Field of vicw & $90^{\circ}$ \\
& Direction of view & $0^{\circ}$ (Forward viewing) \\
& Depth of field & $3 \sim 50 \mathrm{~mm}$ \\
Distal end & Outer diameter & $5.3 \mathrm{~mm}$ \\
Bending section & Rangc of tip bending & Up $210^{\circ}$, Down $90^{\circ}$ \\
Insertion tube & Outer diameter & $5.1 \mathrm{~mm}$ \\
Working length & & $355 \mathrm{~mm}$ \\
Total length & & $660 \mathrm{~mm}$ \\
\hline
\end{tabular}

Cystoscopy suites are frequently located far from the main operating room, sometimes on a different floor and occasionally in a different building. In such situations it is helpful to know that a flexible cystoscope which is readily available in most cystoscopy suites may be recruited as an aid for laryngoscopy in case of a difficult intubation.

Vinod Malhotra MD

Department of Anesthesiology

The New York Hospital-

Cornell University Medical Center

525 East 68th Street

New York City, N.Y. 10021

\section{REFERENCE}

1 Olympus Corporation. 4 Nevada Drive, Lakc Success, N.Y. 11042-1179, U.S.A

\section{Pharyngeal foreign body}

To the Editor:

We would like to report a case of an unusual laryngopharyngeal foreign body. A 28-yr-old native man presented to our institution with dyspnoea, aphonia and dysphagia. He was well until the night before admission. When he awoke at about 0300 he was "vomiting" blood and complaining of shortness of breath. The patient had not been drinking alcohol and otherwise felt well. At 0430 he was assessed and subsequently discharged from his local hospital without treatment. Later that morning he came to Winnipeg for a scheduled medical appointment and, because of his continued dyspnoea, was sent to the emergency department.

Examination showed a man sitting up and unable to control his oral secretions. He was dyspnoeic but not stridorous, and was afebrile. An ENT consultation was obtained and indirect laryngoscopy showed a normal epiglottis, with pus and mucus pooling above the glottis. The vocal cords were not seen. The neck was supple but surgical emphysema was palpable over the anterior neck. The clinical diagnosis was a deep neck abscess with impending airway obstruction and the patient was taken to the operating room for emergency intubation or tracheos- 


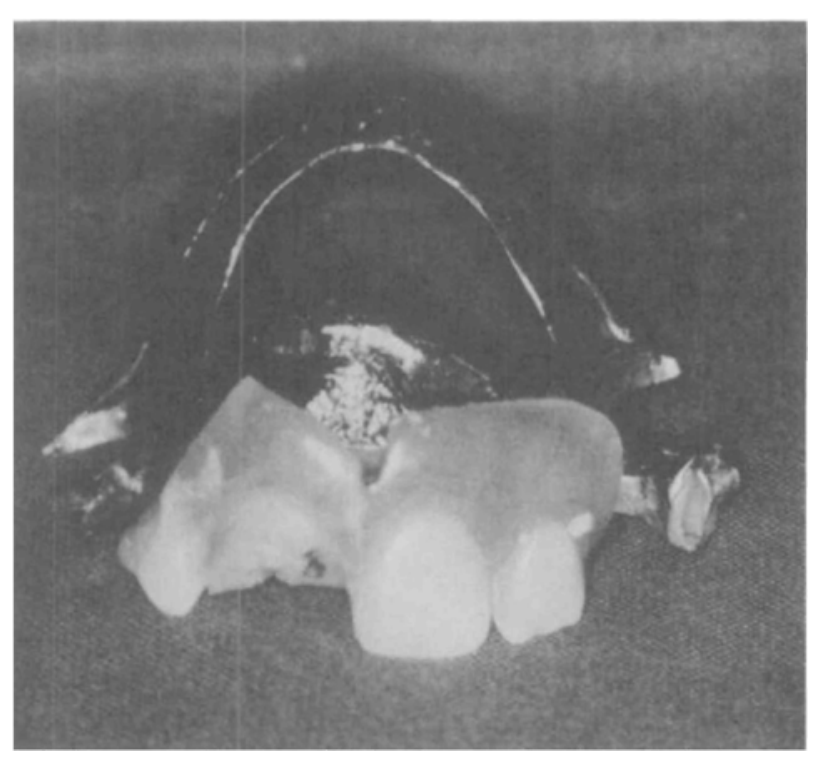

FIGURE Partial denture removed from laryngopharynx.

tomy. $X$-rays were not obtained in the emergency room because of the clinical urgency.

In the operating room, the patient was given oxygen by mask and kept in the sitting position whilst a blood pressure cuff, ECG, and pulse oximeter were applied. After topicalization of the airway with nebulized $4 \%$ xylocaine for five minutes, fibreoptic laryngoscopy was performed. There were several areas of whitish irregularity, suggestive of pus, on the posterior glottis and pharynx above the vocal cords. Fibreoptic laryngoscopy was abandoned because of the possibility of pharyngeal abscess rupture. Lidocaine was then sprayed on the orophar$y n x$ and direct laryngoscopy was performed. Suctioning of the pharyngeal secretions improved visualization and the anaesthetist found that the area of whitish irregularity was a foreign body impacted above the glottis (Figure). A Magill forceps was used to extract a partial denture and, following this, the patient immediately improved. Palpation of the posterior pharyngeal wall revealed no fluctuation but surgical emphysema was noted there as well as in the anterior neck. The patient did well on medical therapy and was discharged several days later.

Foreign body aspiration is recognized as a common cause of stridor and dyspnoea in children. ${ }^{5}$ Unfortunately it is often overlooked in adults presenting with airway complaints. Bones in food ${ }^{3}$ as well as dental appliances ${ }^{2}$ have been reported as causes of upper airway obstruction. The delay in diagnosis may be as long as three years. ${ }^{1,3}$ Our case illustrates the importance of maintaining a high index of suspicion for foreign bodies in the upper aerodigestive tract in any patient presenting with acute onset of dysphagia or shortness of breath. We have also demonstrated the superiority of careful direct laryngoscopy over both indirect and fibreoptic examinations in making this diagnosis.

\section{Joseph C Dort MD}

Department of Otolaryngology

Timothy Yeh MD

Department of Anesthesia

University of Manitoba

Health Sciences Centre

Winnipeg, Man. R3E 1Y9

\section{REFERENCES}

1 Humphries CT, Wagener JS, Morgan WJ. Fatal prolonged foreign body aspiration following an asymptomatic interval. Am J Emerg Med 1988; 6: 611-3.

2 Blaschke $U$, Cheng $E Y$. Foreign body in upper airway: unsuspected cause of obstruction. Postgrad Med 1989; 86: 235-17.

3 Casson $A G$, Guy JRF. Foreign-body aspiration in adults. Can J Surg 1987, 30: 193-4.

4 White $R D$. Foreign body airway obstruction: considerations in 1985. Circulation 1986; 74 (Suppl. IV): 60-2.

5 Poole SR, Mauro RD, Fan LL, Books J. The child with simultaneous stridor and wheezing. Ped Emerg Care 1990; 6: 33-7.

\section{Relationship between $\mathrm{PaCO}_{2}-\mathrm{PETCO}_{2}$ gradient and physiological dead space}

\section{To the Editor:}

We read with interest the recent paper entitled "Weaning from ventilation after cardiopulmonary bypass: evaluation of non-invasive technique."1 Certain statements made in the introduction and discussion of the paper require further clarification.

Firstly, in the introduction, the authors state that in anaesthetized patients the $\mathrm{PaCO}_{2}-\mathrm{PETCO}_{2}$ is always increased. ${ }^{1}$ This is not always true. It has been shown that zero or negative values can occur in normal and other circumstances in patients during general anaesthesia. ${ }^{2-7}$

Secondly, in the discussion they state that factors which affect dead space also alter $\mathrm{PaCO}_{2}-\mathrm{PETCO}_{2}$. This may not always be true as increase in dead space may not necessarily result in an increase in the gradient. For example, following cardiac bypass (CPB), it has been shown that alveolar dead space increased significantly by the end of CPB without any significant change in 